\title{
ASTHMA: A STUDY IN PROGNOSIS OF 1,000 PATIENTS
}

\author{
BY \\ A. G. OGILVIE \\ From the Royal Victoria Infirmary, Newcastle upon Tyne
}

(RECEIVED FOR PUBLICATION MARCH 1, 1962)

\section{The Prognosis in Asthma}

It is not easy to find adequate information about the prognosis in asthma. The condition is notoriously liable to spontaneous variation, the disease is not always clearly defined, and most studies have been small, only covering short periods. In this paper I report a follow-up of 1,000 patients with asthma seen by me over a period of more than 25 years at the Royal Victoria Infirmary, Newcastle.

\section{Material}

These patients were all referred to me by their doctors since there is no hospital asthma clinic. Some had attended the ordinary medical outpatient clinic before 1935 , but most came after 1935 , and the first 1,000 who had completed adequately a questionnaire about their present health were chosen. Only those details which were clearly recorded at the initial interview were used in the analysis.

When this series started, specialized psychiatric advice was not readily available. This may have been an advantage since inaccuracies and misleading results might occur if there were a comparison of psychiatric diagnosis in 1935 with psychiatric assessment to-day.

The patients were given an explanation of the disorder, reassurance, and an account of the remedial measures available. Emphasis was placed on the part which an individual patient must play in his or her own treatment and on co-operation in physiotherapeutic procedures, and a reassuring and reasonable attitude was adopted. Parents and relations needed this; it always included 'debunking' the asthma bogey, since I dislike the pretence that the condition is not asthma at all. Other remedies, medicinal and specific, were advised as seemed wise and feasible, anti-allergic hygiene was included, and experience alone dictated treatment.

\section{DEFINITIONS}

Bronchial Asthma.-This is a condition characterized by recurrent bouts of wheezing, mainly or entirely expiratory, with an associated variable degree of difficulty in breathing and of expiratory obstruction. Although the intervals between these bouts are often symptom-free, yet a ventilatory defect may sometimes be detected by special methods (Engström, Escardo, Karlberg, and Kraepelien, 1959; Strang, 1961). If the asthma had symptom-free intervals it was considered intermittent, and if wheezing and dyspnoea persisted it was called continuous. These terms are purely descriptive, and are not intended to carry any particular significance such as is implied in extrinsic and intrinsic asthma (Rackemann, 1950).

At an international symposium at the University of Groningen (Orie and Sluiter, 1961) it was agreed that " asthma refers to the condition of subjects with widespread narrowing of the bronchial airways, which changes its severity over short periods of time either spontaneously or under treatment, and is not due to cardiovascular disease." My definition is similar to this, though I have used clinical language so that intermittent and continuous types can be included. An eosinophilia was not regarded as an essential finding (even though eosinophils are found with greater frequency in the sputum of asthmatics) since its presence did not confirm the diagnosis, and its absence, particularly during bronchopulmonary infection, did not refute the diagnosis.

Chronic Bronchitis.-This is a condition with cough and phlegm persistent throughout the winter or throughout the year, with a minimum duration of two years. The absence of other diseases of the lungs is implicit (Ogilvie and Newell, 1957a ; Fletcher, 1959). In asthmatics a cough is not normally a prominent symptom and occurs only during and after attacks.

RECURRENT BRonchial InfECTION.-This is a frequently recurrent and febrile chest condition occurring usually in children or adolescents and often associated with asthmatic exacerbation. Such an illness responds well to antibiotic treatment, and the asthmatic reaction is relieved. Here 
this condition is called "recurrent bronchitis." This is different from "childhood bronchitis" in which bronchopneumonia or a severe attack of bronchitis is followed by a persistent cough with phlegm. There is mild febrile exacerbation, usually without bronchiectasis, but occasionally with a few dilated segmental bronchi. These two groups of recurrent and childhood bronchitis have been included with chronic bronchitis in the initial analysis, but receive special attention later as their prognosis differs from that of the chronic bronchitic.

Allergic SENSITIVITY.-This was recognized as a significant feature if one or both of the following requirements were satisfied:

1. A clear history was given of repeated recurrence or aggravation of symptoms after contact with one or more allergens.

2. A strongly positive skin reaction, i.e., an irregular weal of a diameter of at least $10 \mathrm{~mm}$. associated with erythema, was obtained to the prick or the intradermal administration of a standard testing solution.

Desensitization.-I prefer this name to the less euphonious though more correct term hyposensitization for treatment designed to reduce the sensitivity of an individual to a specific substance or substances.

AgE OF ONSET.-This has been variously defined (Fagerberg, 1957; Flensborg, 1945; Baagøe, 1931). Many will accept the onset only when clinically clear-cut asthmatic attacks occur, even though in many patients recurrent respiratory symptoms have been noted for years previously. This seems to me to be unfortunate. Symptoms, particularly in early childhood, often fall short of gross wheezing. There are frequent attacks of "bronchitis", consisting of cough with or without dyspnoea, which last from a few hours to a week. The child is not ill, or "felled" as we call it up here in the north-east. He coughs and may occasionally vomit clear phlegm. There may be a mild rectal pyrexia, the distinction from an attack of acute bronchitis is quite sharp, and an eosinophilia can be found. Wheezing is present, but often only on auscultation.

In my patients, this period of recurrent coughing spells has been noted to precede frank asthma by several years, whilst in adults with continuous asthma a persistent wheeze has sometimes been observed as a mode of onset before the occurrence of obvious asthmatic attacks. The age of onset has been dated from such early symptoms, and it has not been difficult to determine.
Present Health.-This was classified into four groups.

A (Good).-Most of these patients had been entirely free from symptoms for at least two years. Other less perfect individuals are included, since I have allowed a few mild asthmatic attacks provided they did not cause disability on more than seven days in the year. Moderate continuous dyspnoea, interfering with the patient's life to a minimal extent, was also permitted, as was a moderate productive cough.

B (Fair).-Patients in this grade suffered constantly or repeatedly from their disorder. They had recurrent asthmatic attacks, which were often severe, about once a month. They were usually, though not necessarily, persistently breathless up to the degree allowed in Fletcher's grade II (Fletcher, 1952). None of the employed persons were allowed to lose more than a total of four weeks' work on average per year. Housewives presented some difficulty, but if ordinary housework could be done, even though by an extra effort, then they were admitted.

C (Poor).- In this grade there was severe recurrent asthma, always continuous between attacks, with breathlessness amounting to grade III or above, and an annual loss of work of more than four weeks. Many patients had been unable to work at all for a number of years, and some were completely disabled. A patient who was maintained on steroid therapy of necessity was placed in this grade, even if his condition was reasonably satisfactory.

D (Dead).-These patients had died from status asthmaticus, bronchopneumonia, cor pulmonale, or emphysema. Those in whom the chest condition played no part in the fatal issue, e.g., war casualties, have been excluded entirely from the analysis ; two patients who died of carcinoma of the bronchus and one dying of pulmonary tuberculosis have also been excluded.

\section{METHOD}

The record was a four-page folder which was read page by page personally by the author, and the details abstracted in sequence. Only after this was the questionnaire opened, so no subconscious bias should have influenced the analysis. It was annoying when the questionaire was found to be blank or useless, as it was on less than three dozen occasions : the careful return of a blank questionnaire is an interesting phenomenon. 


\section{RESULTS}

Table I shows the composition of the series. There are rather more men than women, but this is not likely to be a source of inaccuracy as analyses have shown no significant clinical differences. between the sexes. The average duration of male and female cases is similar, as is the average follow-up period.

TABLE I

ASTHMA FOLLOW-UP: DETAILS OF SERIES 1,000 patients $\left\{\begin{array}{l}562 \text { males } \\ 438 \text { females }\end{array}\right.$

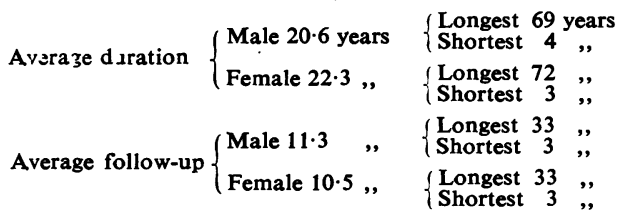

There is little difference in present health between the sexes (Table II), and such difference as there is is not significant. Since sex did not appear to be a factor in prognosis, and since in all subsequent analyses men and women showed negligible differences, they have been grouped together.

TABLE II

SEX IN RELATION TO PRESENT CONDITION

\begin{tabular}{lccccc}
$\begin{array}{c}\text { Present } \\
\text { Health }\end{array}$ & $\begin{array}{c}\text { A } \\
\text { (Good) }\end{array}$ & $\begin{array}{c}\text { B } \\
\text { (Fair) }\end{array}$ & $\begin{array}{c}\text { C } \\
\text { (Poor) }\end{array}$ & $\begin{array}{c}\text { D } \\
\text { (Dead) }\end{array}$ & Total \\
\hline Male & $302(54 \%)$ & $117(21 \%)$ & $99(18 \%)$ & $44(7 \%)$ & 562 \\
Female & $181(44 \%)$ & $139(32 \%)$ & $90(20 \%)$ & $28(4 \%)$ & 438 \\
Total & $483(48 \%)$ & $256(26 \%)$ & $189(19 \%)$ & $72(7 \%)$ & $1,000(100 \%)$
\end{tabular}

The outlook in those patients with the onset before 16 years of age is much more favourable than in those with the onset at 16 or over (Table III). This has been noted in other series (Rackemann and Edwards, 1952 ; Unger, 1945 ; Flensborg, 1945).

TABLE III

AGE OF ONSET IN RELATION TO HEALTH

\begin{tabular}{lccccr}
$\begin{array}{c}\text { Present } \\
\text { Health }\end{array}$ & $\begin{array}{c}\text { A } \\
\text { (Good) }\end{array}$ & $\begin{array}{c}\text { B } \\
\text { (Fair) }\end{array}$ & \multicolumn{1}{c}{$\begin{array}{c}\text { (Poor) } \\
\text { (Dead) }\end{array}$} & \multicolumn{1}{c}{ Total } \\
\hline Under 16 & $375(60 \%)$ & $146(23 \%)$ & $87(14 \%)$ & $16(3 \%)$ & 624 \\
$16-$ & $108(29 \%)$ & $110(29 \%)$ & $102(27 \%)$ & $56(15 \%)$ & 376 \\
$\quad$ Total & $483(48 \%)$ & $256(26 \%)$ & $189(19 \%)$ & $72(7 \%)$ & 1,000
\end{tabular}

The proportion of patients with an early onset in Group $A$ is more than twice as great as those with a later onset. Thereafter there is a steady reversal of this position as we pass from the well, through the poorly, to the dead. The percentage of those with late onset who are dead is five times that of those with an early onset. Most authors have recognized a number of onset periods, such as 0 to 5,6 to 10 , and so on, but $I$ thought that a single age limit was likely to show a clearer and more obviously significant result if indeed a difference in prognosis was to appear, and this decision seems to have justified itself.

Table IV shows that four out of five of those with intermittent asthma are affected before 16

\section{TABLE IV}

AGE OF ONSET IN RELATION TO SYMPTOMS WHEN FIRST SEEN

\begin{tabular}{lccc} 
Symptoms & Intermittent & Continuous & Total \\
\hline Under 16 & $320(81 \%)$ & $304(51 \%)$ & $624(62 \%)$ \\
$16-$ & $85(19 \%)$ & $291(49 \%)$ & $376(38 \%)$ \\
\multicolumn{1}{c}{ Total } & $405(40 \%)$ & $595(60 \%)$ & 1,000
\end{tabular}

years of age, whereas only half of the continuous asthmatics show this early onset. It is evident that intermittent asthma, probably closely resembling Rackemann and Edwards's (1952) ' extrinsic' asthma, is associated with an early onset.

Table $\mathrm{V}$ shows the present health of the patients, divided into the intermittent and continuous type of asthma, according to their condition when first seen. The outlook is much better in the intermittent group.

TABLE V

CLINICAL TYPE IN RELATION TO PRESENT HEALTH

\begin{tabular}{cccccc}
$\begin{array}{c}\text { Clinical } \\
\text { Type }\end{array}$ & $\begin{array}{c}\text { A } \\
\text { (Good) }\end{array}$ & $\begin{array}{c}\text { B } \\
\text { (Fair) }\end{array}$ & $\begin{array}{c}\text { C } \\
\text { (Poor) }\end{array}$ & $\begin{array}{c}\text { D } \\
(\text { Dead) }\end{array}$ & Total \\
\hline $\begin{array}{c}\text { Inter- } \\
\text { mittent }\end{array}$ & $263(65 \%)$ & $89(22 \%)$ & $43(10 \%)$ & $10(2 \%)$ & $405(40 \%)$ \\
$\begin{array}{c}\text { Contin- } \\
\text { uous }\end{array}$ & $220(37 \%)$ & $167(29 \%)$ & $146(25 \%)$ & $62(9 \%)$ & $595(60 \%)$ \\
Total & $483(48 \%)$ & $256(26 \%)$ & $189(19 \%)$ & $72(7 \%)$ & 1,000
\end{tabular}

When Tables III and IV are placed side by side, the good resemblance is evident.

A further study of the intermittent and continuous asthmatics showed another point of wide difference between them. A negligible proportion of those with bronchitis when first seen were intermittent, while those asthmatics without bronchitis were evenly divided between the intermittent and continuous groups (Table VI).

TABLE VI

INCIDENCE OF BRONCHITIS IN RELATION TO CLINICAL

\begin{tabular}{ccc} 
Clinical Type & $\begin{array}{c}\text { TYPE } \\
\text { Bronchitis }\end{array}$ & No Bronchitis \\
\hline Intermittent & 14 & 391 \\
Continuous & 290 & 305 \\
Total & 304 & 696
\end{tabular}

The development of bronchitis in an asthmatic tends to convert the intermittent into the continuous type, and this is suggested by the later tables in this series. It is a partial explanation of the high proportion of continuous asthmatics who had bronchitis when first seen, but only a partial explanation, since $52 \%$ of continuous 
asthmatics had no bronchitis. However, the continuous asthmatic is several times more liable to bronchitis than is the intermittent case.

A confirmation of this suggestion is seen when Table VII is studied. This shows those patients, not bronchitic when first seen, who were found

TABLE VII

PATTERN OF SYMPTOMS AND DEVELOPMENT OF BRONCHITIS DURING PERIOD OF FOLLOW-UP

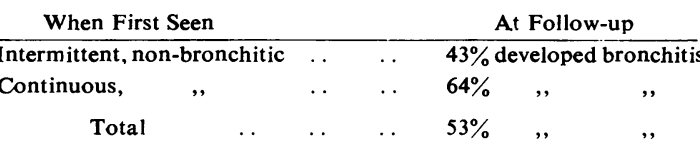

to have become bronchitic at follow-up. The number is considerable, and both intermittent and continuous asthmatics are involved. But the continuous asthmatic is more liable to develop bronchitis than is the bronchitic (two-thirds against two-fifths).

Perhaps the most important figure is the last, which shows that $53 \%$ of non-bronchitic asthmatics developed bronchitis over the years. The seriousness of this will be seen when we study the influence of bronchitis on prognosis.

Table VIII gives the net gain in bronchitis for the whole series and shows that the original position is nearly reversed. Whereas only $30 \%$ had bronchitis when first seen, $60 \%$ had bronchitis on follow-up.

\begin{tabular}{ccc}
\multicolumn{3}{c}{ TABLE VIII } \\
INCIDENCE & $\begin{array}{c}\text { OF } \\
\text { BRONCHITIS INITIALLY } \\
\text { FOLLOW-UP } \\
\text { Bronchitis }\end{array}$ & AND AT \\
\hline When first seen & $304^{*}(30 \%)$ & $696(70 \%)$ \\
At follow-up & $607(61 \%)$ & $393(39 \%)$ \\
$* 113$ recurrent and childhood bronchitis.
\end{tabular}

Table IX shows the final condition at follow-up, comparing the health of the bronchitic directly with that of the non-bronchitic. The difference is a remarkable one. No less than $92 \%$ of the non-bronchitics are in good health, as has been

TABLE IX CHRONIC BRONCHITIS AND BRONCHIAL INFECTION AT
FOLLOW-UP IN RELATION TO PRESENT CONDITION

\begin{tabular}{|c|c|c|c|c|c|}
\hline & $\stackrel{\mathrm{A}}{\text { (Good) }}$ & $\underset{\text { (Fair) }}{\mathbf{B}}$ & $\begin{array}{c}\mathrm{C} \\
\text { (Poor) }\end{array}$ & $\stackrel{\text { D }}{\text { Dead) }}$ & Total \\
\hline $\begin{array}{l}\text { Bron- } \\
\text { chitis }\end{array}$ & $120(20 \%)$ & $228(38 \%)$ & $187(30 \%)$ & “ 72 " $(12 \%)^{*}$ & $607(60 \%)$ \\
\hline $\begin{array}{l}\text { No bron- } \\
\text { chitis }\end{array}$ & $363(92 \%)$ & $28(7 \%)$ & $2(1 \%)$ & “ $0 "(0 \%)^{*}$ & $393(40 \%)$ \\
\hline Total & $483(48 \%)$ & $\begin{array}{l}256(26 \%) \\
\text { This is refe }\end{array}$ & $\begin{array}{l}189(19 \%) \\
\text { erred to in tl }\end{array}$ & $\begin{array}{l}72(7 \%) 1,0 \\
\text { he text. }\end{array}$ & $000(100 \%)$ \\
\hline
\end{tabular}

defined in this article, whereas only one-fifth of the bronchitics qualified for this grade.

In column $\mathrm{D}$, all the deaths have been placed in the 'bronchitic box,' but this figure is put in inverted commas. Many of these deaths took place years ago, and it has not always been possible to obtain information from the doctor about the patient's health in the years before death or even the exact cause of death. In these circumstances information from relatives has been accepted. Sometimes detailed answers were received which could be accepted as reliable, but at other times all that could be decided was that the patient had been 'chesty' for years and that he had died of chest trouble. Since such information is imprecise, all the fatal cases have been put together.

It is known that asthmatics may die of uncomplicated status asthmaticus, and Williams and Leopold (1959) have reported in detail a series of such cases. Williams (1953), in a review of 165 cases verified at necropsy (including 25 of his own), concluded that infection was a dominant cause of death in status asthmaticus. A study has been made of the deaths among asthmatic patients in the Royal Victoria Infirmary during the five years 1956 to 1960 , together with other series reported in the literature, in all of whom full necropsy reports were available (Cardell and Bruce Pearson, 1959 ; Gay, 1946 ; Robertson and Sinclair, 1954 ; Thieme and Sheldon, 1938). The total number is 169,128 of whom showed clear evidence of bronchopulmonary infection. The remaining 41 showed the changes of status asthmaticus only, and so $25 \%$ to $30 \%$ of the deaths in these asthmatics were due to uncomplicated asthma, comparable with Bullen's (1952) series, in which one-third of the 132 necropsies showed death to be due to uncomplicated asthma. If this were the proportion in the present series, from 18 to 24 of the 72 should have been placed in the 'no-bronchitis box.' Even so, Table IX suggests that the development of bronchitis has a most unfavourable influence on bronchial asthma.

We now have to consider an important group of cases. Fifty-four patients out of 304 with bronchitis (or bronchial infection) were found on follow-up to have lost their bronchitis ; 21 were females and 33 were males. All were in the A (good health) group with two exceptions; one man and one woman were graded as B (fair). This result may be compared with Table IX. It is almost identical with that of the "no bronchitis 'group, and suggests that to lose bronchitis is as favourable a prognostic feature as the development of bronchitis is unfavourable. Table $X$ shows a breakdown of these patients according to the kind of bronchial infection which they had 
TABLE X

PATIENTS LOSING BRONCHITIS DURING FOLLOW-UP PERIOD

\begin{tabular}{lcc}
\multicolumn{1}{|c}{ Initial Condition } & $\begin{array}{c}\text { Total } \\
\text { No. }\end{array}$ & $\begin{array}{c}\text { No. Losing } \\
\text { Bronchitis }\end{array}$ \\
\hline $\begin{array}{l}\text { Chronic bronchitis } \\
\begin{array}{l}\text { Recurrent and child- } \\
\text { hood bronchitis }\end{array}\end{array}$ & 191 & 13 \\
$\quad 113$ & 41 \\
$\quad$ Total & 304 & 54
\end{tabular}

when first seen: in only 13 of the 54 was chronic bronchitis of the adult type present.

These 13 patients are of interest since bronchitis is usually thought to be progressive, and it has been shown in this series to have an unfavourable prognostic effect in the asthmatic. They represent only $5 \%$ of the total who were bronchitic when first seen and $1.3 \%$ of the whole series, but they are significant in that they indicate that even wellestablished bronchitis can sometimes remit. In a study of bronchitis in Newcastle upon Tyne (Ogilvie and Newell, 1957b) it was found that 5\% of male and $9 \%$ of female bronchitics considered that their health was improving.

The other 41 patients whose bronchial symptoms had cleared up were all young and were mostly first seen as children. In 20 of them the condition was one of recurrent bronchitis (see Definitions). These illnesses are treated nowadays by antibiotics, and in 12 patients this could have influenced the outcome. The other 21 patients had childhood bronchitis. There were only 133 of these recurrent and childhood bronchitics in the series, and since 41 improved, the recovery rate is high $(36 \%)$, which is unexpected in view of the tendency of the asthmatic person to develop chronic pulmonary infection, which has been shown so clearly in the present series.

I attribute it partly to the fact that these patients were all children or adolescents, and partly to the antibiotic treatment which at least 12 of the children had, but I think that some other unknown factor or factors also played a part.

Those with recurrent and childhood bronchitis who did not show this recovery mostly developed ordinary chronic bronchitis, except for three who acquired bronchiectasis.

Three hundred and forty-eight of the 1,000 patients showed evidence of allergic sensitivity (Table XI). This is $35 \%$, and is only a little less

\section{TABLE XI}

ALLERGIC SENSITIVITY IN RELATION TO PRESENT

\begin{tabular}{|c|c|c|c|c|c|}
\hline & \multicolumn{3}{|c|}{ ONDITION } & \multirow[b]{2}{*}{$\underset{\text { (Dead) }}{\mathbf{D}}$} & \multirow[b]{2}{*}{ Total } \\
\hline & $\stackrel{\mathrm{A}}{\text { (Good) }}$ & $\underset{\text { (Fair) }}{\mathbf{B}}$ & $\stackrel{\text { (Poor) }}{\mathbf{C}}$ & & \\
\hline & $196(56 \%)$ & $79(23 \%)$ & $59(17 \%)$ & $14(4 \%)$ & \\
\hline allergy & $287(44 \%)$ & $177(27 \%)$ & $130(20 \%)$ & $58(9 \%)$ & 6 \\
\hline Total & $483(48 \%)$ & $256(26 \%)$ & $189(19 \%)$ & $72(7 \%)$ & 1,00 \\
\hline
\end{tabular}

than that observed by Rackemann and Edwards (1952), who reported $40 \%$ in their series of 688 patients.

This suggests that the criteria of diagnosis in bronchial asthma used in the United States may not differ so widely from those applied in the United Kingdom as is often thought. The prognostic influence of allergic sensitivity is seen to be quite moderate. Those with allergic sensitivity do a little better than the others, but the difference is marginal.

Treatment by desensitization had no effect on long-term prognosis, although usually the immediate result was beneficial (Table XII). This

TABLE XII

\begin{tabular}{|c|c|c|c|c|c|}
\hline \multicolumn{2}{|c|}{$\begin{array}{l}\text { DESENSITIZATION } \\
\text { RELATION }\end{array}$} & N $\underset{\text { TO }}{\text { OF }}$ & $\begin{array}{l}\text { ALLERGIC } \\
\text { PRESENT }\end{array}$ & \multicolumn{2}{|c|}{$\begin{array}{l}\text { ASTHMATICS } \\
\text { HEALTH }\end{array}$} \\
\hline $\begin{array}{l}\text { Treat- } \\
\text { ment }\end{array}$ & $\mathbf{A}$ & B & $C$ & & To \\
\hline & & & & & \\
\hline & & & & & 2 \\
\hline otal & $6(56 \%)$ & $79(23 \%)$ & $59(17 \%)$ & $14(4 \%)$ & $348\left(100^{\circ}\right.$ \\
\hline
\end{tabular}

is in line with the experience of McAllen (1961), who studied the effect of treatment both by the subcutaneous and by the endobronchial routes: those who improved were found to have returned to their original condition in about six months. The conclusion must be that whatever part allergic sensitivity may play in the course of bronchial asthma, it is not a factor of major importance in long-term prognosis. It also seems as if desensitization as a means of treatment plays only a minor role in the determination of the health of the patient in later life, effective though it often is in the short term.

\section{Discussion}

The chief difficulty in discussing the natural history and outcome of the asthmatic state is the wide variation in approach, in diagnosis, and in classification which is to be found in the extensive literature. I have made reference to the literature only when essential, and many important contributions have been discussed briefly or not at all.

Vaughan and Black (1954) emphasize the unreliability of insurance and other official analyses, and sum up the prognosis in quite a general way. They recognize "the continuous form and the spasmodic or intermittent," and go on to say that "the life span of the former may be distinctly shorter than that of the latter." This statement, though unsupported by quoted statistical evidence, accords closely with the conclusions of this study. Fagerberg (1957) emphasizes the 
importance of the age of onset, which he considers has been too much neglected in the past: my results confirm this view even although the definition of onset is not quite the same as his.

The terms 'extrinsic ' and 'intrinsic,' popularized if not actually introduced by Rackemann (1950), probably refer to patients similar to those included in my intermittent and continuous groups respectively, but they cannot be regarded as truly identical groups. The comparison which follows is therefore not exact, but the close similarity in the results perhaps excuses it. They followed 688 asthmatic children for 20 years, divided them into two groups, the 'allergic' and the 'mixed unidentified and bacterial' group. The allergic group (extrinsic) were carefully and meticulously treated on anti-allergic principles, and the others in other ways. The object was to demonstrate the influence of intensive treatment, and the allergic group seem to be the best group to take for comparison. It is difficult to be certain that their ' cured or relieved,' ' mild or moderate,' and 'severe' groups are closely similar to the A, B, and $C$ groups of this series, but assuming that they are, we see how extremely close the result is to that in the Newcastle intermittent cases (Table XIII).

TABLE XIII

A COMPARISON OF RACKEMANN AND EDWARDS "ALLERGIC" GROUP WITH THE NEWCASTLE "INTER-

\begin{tabular}{lcccr} 
Present Health & $\begin{array}{c}\text { A } \\
\text { (Good) }\end{array}$ & $\begin{array}{c}\text { B } \\
\text { (Fair) }\end{array}$ & $\begin{array}{c}\text { C } \\
\text { (Poor) }\end{array}$ & $\begin{array}{c}\text { D } \\
\text { (Dead) }\end{array}$ \\
\hline $\begin{array}{l}\text { Rackemann } \\
\text { and Edwards }\end{array}$ & $178(64 \%)$ & $78(27 \%)$ & $19(7 \%)$ & $5(2 \%)$ \\
Newcastle & $263(65 \%)$ & $89(22 \%)$ & $43(10 \%)$ & $10(2 \%)$
\end{tabular}

In the classification of Vaughan and Black (1954) and of Unger (1945), the terms paroxysmal and chronic seem to be identical with those used in the Newcastle series, but other difficulties in comparison arise.

Rackemann and Edwards' (1952) mixed group cannot of course be compared with the continuous group. But if we take this whole series and compare it with the 624 Newcastle patients in whom the onset was before the age of 16, Table XIV is the result.

\section{TABLE XIV}

A COMPARISON OF RACKEMANN AND EDWARDS' SERIES WITH THE NEWCASTLE PATIENTS WHOSE ONSET

\begin{tabular}{|c|c|c|c|c|}
\hline resent Health & $\stackrel{\mathbf{A}}{\text { (Good) }}$ & $\underset{\text { (Fair) }}{\mathbf{B}}$ & $\begin{array}{c}\mathrm{C} \\
\text { (Poor) }\end{array}$ & $\underset{\text { (Dead) }}{\mathbf{D}}$ \\
\hline $\begin{array}{l}\text { Rackemann } \\
\text { and Edwards }\end{array}$ & 7( & ६) & 75 & \\
\hline Newcastle & $375(60 \%)$ & $146(23 \%)$ & $87(14 \%)$ & $16\left(3^{\circ}\right)$ \\
\hline
\end{tabular}

The result is again similar, once more assuming that the criteria are comparable. Such coincidence between the two series of similar size, though widely separated in time and space and differing in the approach to treatment, is striking. It encourages the view that the development of the asthmatic state in Boston and in Newcastle is not very dissimilar. Ryssing's (1959) follow-up of Flensborg's (1945) series is less easy to compare, although the condition on follow-up appears to be less favourable generally. This series was designed purely as a natural experiment, and no special treatment was given: it is impossible to say how this influenced the results.

In my patients, the more favourable outlook for the asthmatic who begins to have symptoms in childhood is confirmed. When asthma begins before 16 the symptoms are intermittent in four out of five, whereas, when the onset is later, only two out of four are intermittent. The intermittent patient has a considerably more favourable prognosis, and this is a probable explanation of the better prospect in those with an early onset (see Table V). When the intermittent and continuous groups were compared, the incidence of bronchitis was initially much higher in the continuous group, and was almost negligible in the intermittent (see Table VI). The incidence of bronchitis and? bronchial infection in the whole series $(30 \%)$ is close to the estimate of Cooke (1947), whose figure was $35 \%$.

Although $53 \%$ of all patients had developed bronchitis during the follow-up period, this tendency was much greater in the continuous group. Only $43 \%$ of the intermittent asthmatics, non-bronchitic initially, developed bronchitis, as against $64 \%$ of the continuous non-bronchitic asthmatics. This means that there is a significant tendency among asthmatics to develop bronchitis, and this tendency is greater in the patient with continuous symptoms. Table IX shows that this constitutes a major factor in prognosis. Of the 393 patients still not bronchitic on follow-up, $92 \%$ qualified for the A or good health label: whereas of the 607 bronchitics only $20 \%$ so qualified.

Fortunately, bronchial infection need not necessarily lead to deterioration, although it usually does so. There were 54 patients with bronchitis and bronchial infection who were found on follow-up to have lost their bronchitis, and with two exceptions these were in the A or good health group. The proportion is $98 \%$, as high as, or higher than, in those who did not develop bronchitis at all (see Table VIII). 
A breakdown of these ' bronchitis losers' shows that in 41 the condition was recurrent or childhood bronchitis. These 41 recoveries in 113 cases of bronchitis in young persons support the view that the outlook is better at this age than when bronchitis develops later in life. Antibiotic treatment was intensively applied in 12 out of the 41 and may have contributed to their recovery, though this does not affect the conclusion since antibiotic treatment was given to numbers of the chronic bronchitics also. Table XIII shows also that even from chronic bronchitis itself recovery is possible, though it is infrequent. Neither allergic sensitivity nor the desensitization treatment given seemed to affect the long-term prognosis (Tables XI and XII).

This study suggests that if we can prevent the development of bronchitis in an asthmatic patient or can relieve him of it should he acquire it, we shall do more for the patient than can be done in any other way.

\section{SUMMARY}

One thousand unselected patients with bronchial asthma have been followed up for an average period of 11 years, with extremes of 33 years and three years. The average period from the first symptoms to the date of follow-up was 20.6 years in the 562 males and 22.3 years in the 438 females, with extremes of 72 years and three years. Since throughout the analysis no differences were found between the sexes, they have been grouped together.

Terms used, such as asthma, chronic bronchitis, childhood bronchitis, age of onset, etc., have been carefully defined, as have the descriptions of intermittent and continuous asthma. The present state of the patients has been classified as A (good), B (fair), C (poor), and D (dead).

Early age of onset (before 16) and intermittent asthma were associated and had a more favourable prognosis, while the childhood bronchitic had a better outlook than the adult bronchitic. Intermittent and continuous asthma have been compared. The incidence of bronchitis initially was higher in the continuous group, and the tendency to develop bronchitis over the years (present in all asthmatics) was also greater in the continuous group. Those with bronchitis were in much poorer health on follow-up than those without.
This suggests that the presence or development of bronchitis in an asthmatic is a serious complication of unfavourable prognostic significance, and conversely that the lesser tendency to bronchitis which has been found in patients with early onset, and in intermittent asthma, is the reason for their better prognosis.

The presence or absence of demonstrable allergic sensitivity and of specific desensitization treatment has no obvious important influence on long-term prognosis.

Of 113 patients with recurrent and childhood bronchitis initially, 41 were found to have lost their bronchitis on follow-up, whereas of 191 with chronic bronchitis, 13 had lost their bronchitis. Fifty-two of these 54 'bronchitis losers' were in good health on follow-up, suggesting that the loss of bronchitis is as favourable a feature as the development of bronchitis is unfavourable.

A chief object of management in bronchial asthma should be the prevention of bronchitis, and the chief aim of treatment should be to rid the patient of bronchitis should he develop it. Other factors are secondary, though important.

\section{REFERENCES}

Baagøe, K. H. (1931). Ugeskr. Laeg., 93, 79. Quoted by Fagerberg. Bullen, S. S. (1952). J. Allergy, 23, 193.

Cardell, B. S., and Bruce Pearson, R. S. (1959). Thorax, 14, 341.

Cooke, R. A. (1947). Allergy in Theory and Practice. Saunders, Philadelphia.

Engström, I., Escardo, F. E., Karlberg, P., and Kraepelien, S. (1959). Acta Paediat. (Uppsala), 48, 114.

Fagerberg, E. (1957). Acta allerg. (Kbh.), 11, 293.

Flensborg, E. W. (1945). Acta Paediat. (Uppsala), 33, 4.

Fletcher, C. M. (1952). Proc. roy. Soc. Med., 45, 577.

- (1959). Thorax, 14, 286.

Gay, L. H. (1946). The Diagnosis and Treatment of Bronchial Asthma. Baillière, Tindall \& Cox, London.

McAllen, Monica K. (1961). Thorax, 16, 30.

Ogilvie, A. G., and Newell, D. J. (1957a). Chronic Bronchitis in Newcastle upon Tyne, p. 13. Livingstone, Edinburgh. (1957b). Chronic Bronchitis in Newcastle upon Tyne, p. 97, E. 10. Livingstone, Edinburgh.

Orie, N. G. M., and Sluiter, H. J. (1961). Bronchitis, p. 281. Royal vangorcum, Assen, Netherlands.

Rackemann, F. M. (1950). J. Amer. med. Ass., 142, 534.

and Edwards, Mary C. (1952). New Engl.J. Med., 246, 815, 858. Robertson, C. K., and Sinclair, K. (1954). Brit.med. J., $1,187$.

Ryssing, E. (1959). Acta Paediat. (Uppsala), 48, 255.

Strang, L. B. (1961). M.D. Thesis. University of Durham.

Thieme, E. T., and Sheldon, J. M. (1938). J. Allergy, 9, 246.

Unger, L. (1945). Bronchial Asthma, p. 38. Thomas, Springfield, Ill.

Vaughan, W. T., and Black, J. H. (1954). Practice of Allergy, 3rd ed. Mosby, St. Louis.

Williams, D. A. (1953). Thorax, 8, 137.

and Leopold, J. G. (1959). Acta allerg. (Kbh.), $14,83$. 